\title{
APROVECHAMIENTOS FORESTALES, ORDENANZAS DE MONTES Y CONFLICTIVIDAD SOCIAL EN EL NORTE DE PALENCIA EN LA EDAD MODERNA (SIGLOS XVII-XVIII)
}

\author{
José María RAMOS SANTOS \\ I.E.S. Campos y Torozos (Medina de Rioseco)
}

Recibido: $12 / 02 / 2008$

Aceptado: 09/11/2009

RESUMEN: Durante la Edad Moderna las relaciones del hombre con el medio forestal para realizar los aprovechamientos fueron intensas y complejas en el área de la Montaña palentina, hasta tal punto que los conflictos de intereses determinaron numerosos pleitos, que adquirieron tal trascendencia que llegaron al Alto Tribunal de la Chancillería de Valladolid. Esta conflictividad es un reflejo de la elevada ocupación de este espacio de montaña, y de las relaciones sociales entre grupos de poder con intereses distintos en el uso y disfrute del monte, desde ganaderos a agricultores o propietarios de ferrerías. El monte constituye el elemento clave en torno al que gira la vida de todas las comunidades rurales de esta extensa zona, pero no todas las comunidades (y todos sus habitantes) se relacionan con el monte de la misma forma.

PALABRAS CLAVE: Pleitos, gestión forestal, ganadería, incendio, monte.

FOREST EXPLOITATION, LAND ORDINANCE AND SOCIAL CONFLICT IN THE NORTH OF PALENCIA IN THE MODERN ERA (17 $7^{T H}$ AND $18^{T H}$ CENTURIES)

ABSTRACT: During the early modern man's relationship with the forest environment for the land use were in the Mountain area palentina intense and complex, so much so that conflicts of interest identified numerous lawsuits, which they acquired such importance that reached the High Court the Chancilleria of Valladolid. This conflict is a reflection of the high occupancy of this space mountain, and social relations of power between groups with different interests in the use and enjoyment of the mountain, from farmers to farmers or owners of forges. The mountain is the key element that revolves around the lives of all rural communities of this vast area, but not all communities (and all its inhabitants) are related to the mountain of the same form.

KEY WORDS: Lawsuits, forest management, cattle, fire, forest.

EXPLOITATIONS FORESTIÈRES, ORDONNANCES DES FORÊTS ET CONFLICTIVITÉ SOCIALE DANS LES RÉGIONS DU NORD DE LA PROVINCE DE PALENCIA ENTRE LE XVII ${ }^{\grave{m} \text { e }}$ ET LE XVIII ${ }^{\text {ème }}$ SIÈCLE

RÉSUMÉ: Pendant l'Âge Moderne les relations de l'homme avec le milieu forestier pour réaliser les profits ont été, dans le domaine de la Montagne palentina, intenses et complexes, à tel point que les conflits d'intérêts ont déterminé des nombreux procès qu'ils ont acquis telle transcendance qu'ils sont arrivés au Haut Tribunal de la Chancillería de Valladolid. Ce conflit est 
un reflet de l'élevée occupation de cet espace de montagne, et des relations sociales entre des groupes de pouvoir avec des intérêts distincts dans l'usage et la jouissance de la montagne, tellement éleveurs comme des agriculteurs ou des propriétaires de forges. La montagne constitue l'élément clef autour de celui qui tourne la vie de toutes les communautés rurales de cette zone étendue, mais non toutes les communautés (et tous ses habitants) se rattachent à la montagne de la même forme.

MOTS-CLÉS: Procès, gestion forestière, élevage, incendie, forêt.

APROVEITAMENTOS FLORESTAIS, ORDENANÇAS DE MONTES E CONFLITOS SOCIAIS NO NORTE DE PALENCIA NA IDADE MODERNA (SÉCULOS XVII-XVIII)

RESUMO: Durante a Idade Moderna as relações do homem com o médio florestal para realizar os aprovechamientos foram no área da Montanha palentina intensas e complexas a tal ponto que os conflitos de interesses determinaram numerosos pleitos, que adquiriram tal trascendencia que chegaram ao Alto Tribunal da Chancillería de Valladolid. Esta conflictividad é um reflito de elevada ocupação deste espaço de montanha, e das relações sociais entre grupos de poder com interesses diferentes no uso e desfrute do monte desde ganaderos a agricultores ou proprietários de ferrerías. O monte constitui o elemento finque em torno do que gira a vida de todas as comunidades rurais desta extensa zona, mas não todas as comunidades (e todos seus habitantes) se relacionam com o monte da mesma forma.

PALAVRAS CHAVE: Pleitos, gestao florestal, ganaderia, incêndio, monte.

\section{INTRODUCCIÓN Y METODOLOGÍA.}

El monte se percibía en la Edad Moderna como un espacio del que obtener recursos; de ahí el interés general en preservarlo, si bien con frecuencia los intereses particulares imponían su criterio o conseguían provocar tensiones que les facilitaban un acceso al monte y sus recursos en condiciones muy favorables. Dado que en las áreas de montaña las superficies forestales estaban ampliamente extendidas, y el terrazgo cultivable era reducido, con frecuencia surgían conflictos por el uso del territorio y la gestión de sus recursos, con lo que la transformación del monte era un fenómeno recurrente. Es posible recurrir a las fuentes historiográficas para comprender cómo era la realidad de la gestión del monte en la Edad Moderna, y cómo resurgen con fuerza conflictos que perduran en el tiempo y son un reflejo de una realidad que a veces se ha pasado por alto. El monte constituía una preocupación generalizada, tanto para quienes veían en él un sustento como para quienes aspiraban a su sustitución por matorrales y pastos (GARCÍA FERNÁNDEZ, 2002, pp. 11-12).

A través de un estudio sistemático de la documentación del Archivo General de Simancas y del Archivo de la Real Chancillería, en este último caso tanto pleitos (civiles y criminales) como óleos o dibujos, es posible, por una parte, reconstruir la dinámica del paisaje vegetal de amplias áreas durante la Edad Moderna, en las que el monte jugó un papel decisivo en la organización del territorio; y, por otra parte, dilucidar el valor cambiante del medio forestal a través de 
los conflictos sociales generados en torno a él a lo largo de los siglos. Estas situaciones de conflictividad adquirieron tal envergadura que con frecuencia se prolongaron durante décadas, y pocas veces pudieron resolverse satisfactoriamente.

\section{LOS USOS Y APROVECHAMIENTOS FORESTALES EN EL NORTE DE PALENCIA: LA CONFIGURACIÓN DE LOS DIVERSOS PAISAJES FORESTALES.}

Aunque ya durante la Alta Edad Media existe una incipiente regulación de la explotación del monte, en relación con un intenso aprovechamiento del mismo, habrá que esperar a los primeros años del siglo XVI para que tanto la preocupación de la Monarquía por la reducción de la superficie forestal, como el aumento de la presión de la Mesta, lleven a una reglamentación máxima con las Ordenanzas municipales (MANUEL VALDÉS, 1999). Esta reglamentación si bien en parte favorece la conservación de las masas forestales, no evitará las continuas talas o incendios (en gran medida aceptados de forma natural) que, de manera periódica, se realizan en los montes. De tal forma que en los siglos siguientes se intensificará la presión normativa, lo que está en relación con un aprovechamiento integral del monte.

Este aprovechamiento llevará, por una parte a una intensa transformación del monte, y por otro a una degradación del mismo, dando entrada a matorrales que colonizan amplias extensiones de terrenos, especialmente en los sectores de media y alta montaña. Así, se entiende la existencia de un Monasterio consagrado a Nuestra Señora del Brezo (priorato del Monasterio de San Zoilo de Carrión) en Villaverde de la Peña desde el siglo XIV, corroborando un predominio del matorral en este espacio de media montaña desde unas fechas muy tempranas. No en vano, también para otras áreas de la montaña cantábrica se han señalado prácticas de roza del monte para tierras de cultivo y pastos desde el último cuarto del siglo XIV (GARCÍA FERNÁNDEZ, 1988, p. 129).

El monte, en todo caso, se conserva en amplias extensiones, pues muchas veces el terreno no ofrece otro recurso ni es posible su cultivo por las fuertes pendientes, mientras que el arbolado ofrece leña, madera y hojas para el ganado, además de refugio en invierno. Así lo reconocen, por ejemplo, los vecinos de Villavega (al Norte de Aguilar de Campóo): "No hay más árboles que los que sólo producen hoja para los ganados [...] a causa de ser este país frío y de poca sustancia su tierra [...]” (AGS. CME. L. 487).

La conflictividad social que se genera en relación con el monte tiene que ver con intereses enfrentados entre grupos sociales o con conflictos entre concejos, pero también con las diversas posibilidades que ofrece el monte, con frecuencia 
incompatibles. En el primer caso las disputas enfrentan a ganaderos con agricultores y carboneros; en el segundo caso los problemas derivan de cambios en los aprovechamientos ocurridos durante los últimos años en términos comunes. Es una situación que tienen sus orígenes en la Alta Edad Media y se continúa durante la Época Moderna, y que es consustancial a otros lugares de montaña de nuestro territorio y de territorios vecinos, como puede comprobarse en la Cordillera Central o en el Macizo Asturiano.

Así, se ha estudiado el impacto sobre el monte en Cantabria en la Edad Moderna, en relación con el auge de la ganadería, la ampliación de los terrenos de cultivos o las necesidades de madera para las ferrerías, que determinan la configuración de un nuevo paisaje forestal y aumentan los conflictos entre particulares, tras los que se esconden, con frecuencia, luchas de poder (EZQUERRA BOTICARIO et al., 2004). Un caso concreto de conflictos relacionados con los usos y aprovechamientos en el monte, lo encontramos en la Cordillera Central en 1560, cuando varios concejos de la Tierra de Ayllón (Segovia) interpusieron un pleito contra el concejo de Ayllón para que se revocasen unas Ordenanzas que protegían el monte de Matallana de la entrada de ganado: el conflicto tiene que ver con el interés de Ayllón para proteger un monte por "la falta que habia de leña y madera por no haber en esa dicha tierra monte [...]", mientras que los ganaderos de los lugares vecinos protestan por la reducción de pastos para sus ganados (ARCHVA. PC. Pérez Alonso (F.). C. 1.021-1).

En este mismo sentido pueden verse algunas situaciones de enfrentamientos por aprovechamientos en el monte en distintos pleitos que afectan a diversas comunidades en el conjunto de la Montaña Palentina.

En 1645 comienza un pleito entre los concejos de Villalba, Guardo, Velilla y Mantinos, que se prolonga hasta 1660, y que tiene como núcleo del problema dilucidar si el concejo de Villalba podía cortar leña y hacer los demás aprovechamientos en los montes de Guardo, Velilla y Mantinos (ARCHVA. PC. Alonso Rodríguez (D.) Caja 356-1). Como en todos los asuntos referentes a los montes los antecedentes se remontan en el tiempo y entran en relación con asuntos de jurisdicción y con antiguos aprovechamientos comunes entre varios municipios, que se han mantenido durante varios siglos, pero de forma confusa. La sentencia del Alto Tribunal de Justicia da la razón al concejo de Villalba en el sentido de que sus vecinos sí podían seguir entrando en los montes de los términos de Guardo, Velilla, Mantinos y Otero de Guardo para efectuar la corta de leña y madera, ésta última con destino a la fabricación de carbón. El problema debió persistir, por la progresiva reducción de los montes y el mantenimiento de los aprovechamientos forestales, lo que algo más de un siglo después, en 1788, ocasionó un nuevo pleito entre estas poblaciones: como prueba de cargo en ese pleito se realizó un óleo que refleja muy bien la localización del monte en am- 
bas márgenes del río Carrión en Velilla, con amplios espacios deforestados y otros en los que se concentran las escasas superficies forestales (Vid. FIG. 1).

Figura 1. Área del término de Velilla de Río Carrión con sus montes en 1788

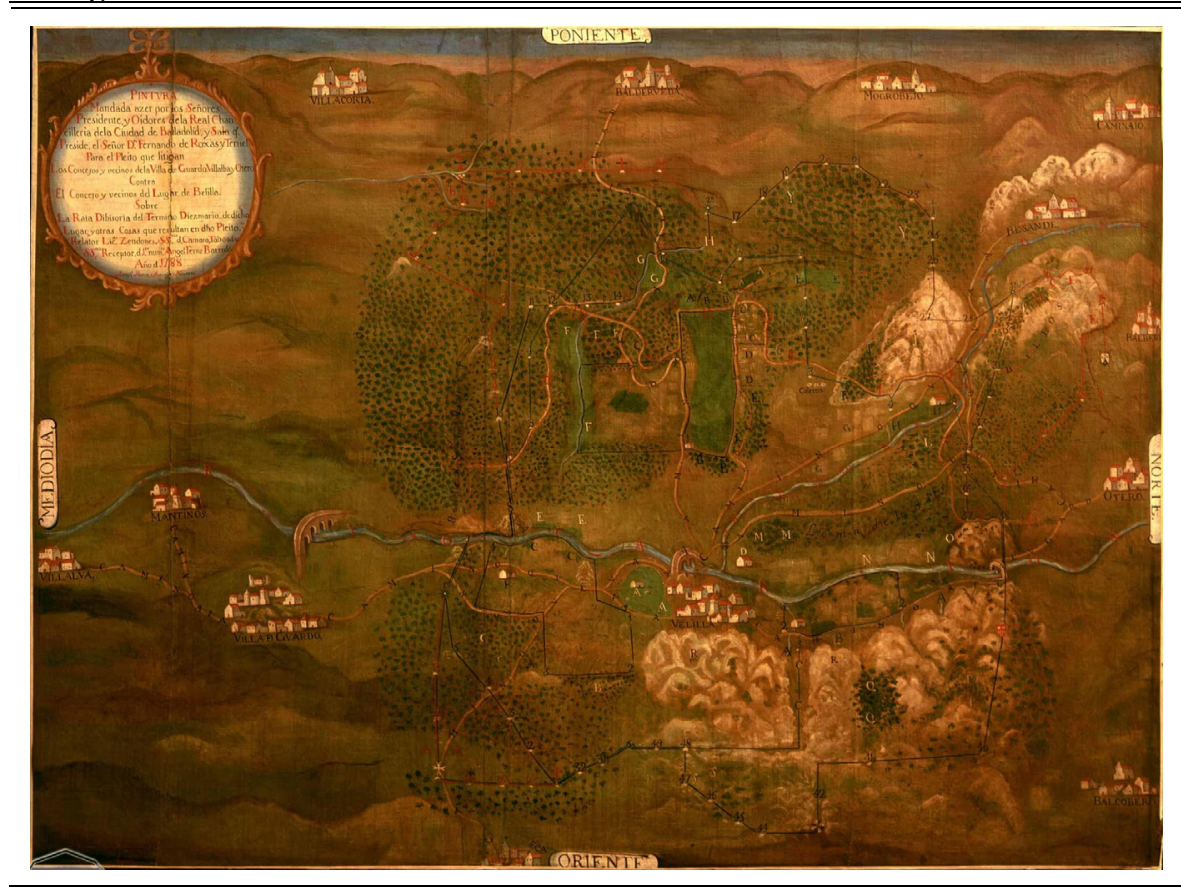

FUENTE: Archivo de la Real Chancillería de Valladolid. Ministerio de Cultura. Planos y Dibujos. Óleos 1.

Así, también sabemos que al menos entre los siglos XVI y XVII los conflictos entre el concejo de Orbó y la localidad de Aguilar de Campóo fueron frecuentes. Conflictos que se sustentan en el alejamiento del monte de la población de Aguilar, lo que dificulta a este concejo la vigilancia de la masa forestal de su propiedad para impedir talas ilegales, y la cercanía de este extenso monte a la pequeña la población de Orbó, con un exiguo término municipal, y por tanto con necesidades de recursos naturales. Las autoridades de Aguilar de Campóo manifiestan de forma rotunda a mediados del siglo XVIII la escasa utilidad de este monte en relación con su alejamiento del núcleo de población: "[...] y su leña no trae utilidad alguna a los vecinos, porque por ordenanza se les permite sacar de él en cada un año cuatro carros de leña de ramada, los más no les traen por la mucha costa que tienen, pues sale más costoso que si se comprara en la plaza pública [...] " (AGS. CME. L. 486). La solución alcanzada pasó porque los vecinos de Orbó tuviesen derecho al aprovechamiento o arrendamiento 
de los pastos del monte, con la obligación de conservar diariamente la leña del mismo; medida conciliadora que persigue un objetivo claramente proteccionista dadas las diferencias existentes entre ambas localidades (AGS. CME. L. 487). El mismo problema debió plantearse en otras localidades, como es el caso de Estalaya, donde, ante la acusación realizada en 1735 por el concejo de Rabanal de los Caballeros, de que vecinos de la primera localidad han cortado numerosos pies de roble para la fabricación de carrales, los vecinos de Estalaya alegan que la madera del monte de Rabanal no les es de ninguna utilidad por estar el monte a más de una legua de distancia (ARCHVA. PC. Fernando Alonso (F.). C. 2.224-1). Más aún, todavía en una fecha tan tardía como es 1819 el concejo de Guardo protesta ante el de Velilla por los abusos que sus vecinos cometen en el monte ValdeAya, en el que ambas poblaciones tienen común aprovechamiento: "[...] por estar el monte más distante de la villa y muy inmediato a Velilla los vecinos de ésta cortan de él a su libertad [...] llegando el exceso hasta para los hornos y fábricas de cal" (ARCHVA. PC. Alonso Rodríguez (F.). C. 1.250-6).

Las diferencias entre Orbó y Aguilar tuvieron tal intensidad que incluso se producen varios incendios entre los años 1668 y 1674 en el Monte Aguilar, incendios que tienen interés por dos motivos: en primer lugar porque debieron ser provocados, según se deduce de la investigación judicial; y en segundo lugar porque parece que remiten a una forma de controlar el crecimiento del matorral inútil como pasto, al tiempo que favorece el desarrollo de matorrales que sí son comidos por el ganado. El desinterés de los vecinos de Orbó por la madera está en relación con la prohibición que tienen de cortarla, aunque se les permite el pasto con su ganados, "por la carga y obligación que tiene de cuidar de la madera de él” (AGS. CME. L. 486).

Uno de los testigos del incendio, vecino de Orbó, después de explicar que sólo se había quemado una séptima parte, continúa argumentando que "importara mucho se hubiera encendido todo él pues con eso se acabaran las malezas de árgoma, espinos y zarzas que impedian el pasto de los ganados y libertad de andar por él" (ARCHVA. PC. Pérez Alonso (F.) C. 2.484-2). En definitiva, se ensalzan los benéficos efectos del fuego sobre un espacio forestal en relación con los aprovechamientos ganaderos. En el siglo XVIII las diferencias parece que estaban en proceso de resolverse, no en vano el acuerdo que se mantenía consiste en que los vecinos de Orbó aprovechen el pasto del monte, y los de Aguilar recojan la leña.

Ese problema de los incendios debió ser recurrente, pues la extensión de los matorrales de brezo y árgoma tiene una clara relación con el incendio y el subsiguiente sobrepastoreo de los matorrales que brotan en el terreo quemado. De hecho, la práctica habitual consistente en el reparto entre los vecinos de leña y de hojas, fundamentalmente de roble y fresno (FLORIDO TRUJILLO, 2004), no 
sólo es un recurso para la economía de los agricultores y ganaderos de la zona, sino que también constituye una fórmula muy práctica para limpiar el monte, eliminando, antes de que caigan las primeras nieves, la leña muerta y las hojas que en verano pueden favorecer los incendios.

Un carácter distinto tuvo el interesante pleito de 1735 entre los concejos de Brañosera y Revilla de Santullán. En este caso el motivo del pleito radica en la acusación del concejo de Brañosera contra varios vecinos de Revilla por haber cortado 31 pies de roble en la majada Valdepicos. Si la entidad de la corta parece reducida, para el concejo de Brañosera representaba una auténtica ruina económica al atentar contra su forma de vida, pues de esa manera se impedía que los ganados vacunos pudiesen refugiarse en la majada, ya que gran parte de los robles cortados correspondían a la cerca que aislaba la majada del bosque (sin duda los habitantes de Brañosera querían impedir que un hecho puntual se convirtiese en costumbre, con las consecuencias negativas que esto entrañaba): "Seguirán muchos y mayores inconvenientes, tan grandes que serán causa para perder las vidas por privarnos de los ganados, que es únicamente con lo que nos mantenemos, por ser la tierra tan fragosa, estéril, que no ha lugar de valernos de otro modo" (ARCHVA. PC. Pérez Alonso (F). C. 2.770-6).

El deterioro ocasionado en la majada tiene además una evidente trascendencia para el futuro pues, según manifiestan los vecinos de Brañosera, tardarán 50 años en crecer árboles de ese tamaño; no en vano las majadas que poseía esta población (cinco en total) no se habían cortado en más de 100 años, constituidas por robles y acebos que las defienden "de las nieves, aires y aguas [...]". Vemos aquí de nuevo como el arbolado cumple una función protectora frente a la Naturaleza, que se muestra hostil durante gran parte del año. En definitiva, a pesar de que los vecinos de Revilla alegarán que la majada tenía suficiente arbolado ("que aunque de ella se sacaran 1.000 pies quedara bastantemente abrigada [...]"), los jueces darán la razón al concejo de Brañosera, tanto en la sentencia de vista, como en la de revista, tras la alegación presentada por Revilla.

En cualquier caso, la corta de árboles se perseguía con especial dureza, especialmente si la corta era por el pie, sin guardar el precepto de corta a horca y pendón: el objetivo era evitar la destrucción del monte pero también favorecer la regeneración del arbolado. Así en 1738 el concejo de Guardo interpone un pleito a varios vecinos de Villalba de Guardo (entre ellos el regidor) por haber cortado leña por el pie en los montes comunes de Guardo. El problema se agrava por el hecho de que esta leña ha sido transformada en carbón vegetal para su venta en Tierra de Campos (en concreto en Villada), de tal forma que el perjuicio es doble, por una parte se ha produce un perjuicio al monte y por otra parte no se benefician los vecinos de Villalba ni de Guardo del suministro de carbón 
de roble, que no debía ser especialmente abundante, dadas las limitaciones para la corta de leña (ARCHVA. PC. Alonso Rodríguez (Olv.). C. 764-5).

Otro problema que generaba tensiones es el que afectaba al tránsito de ganados; así puede constatarse en el pleito que enfrenta a Herreruela de Castillería con Estalaya entre 1772 y 1775: los vecinos de Estalaya impiden todos los años, entre los días 9 y 12 de noviembre, el paso de ganados de Herreruela a Cervera por las praderas de La Reguera, La Vega y la Borreguera; la sentencia resultará favorable a los intereses de Estalaya, de tal forma que si bien tradicionalmente este derecho se había venido utilizando por los vecinos de Herreruela no puede convertirse en definitivo atendiendo a los intereses de los ganaderos de Estalaya (ARChVA. Pleitos Civiles. Pérez Alonso (F.). C. 3.304-4).

\section{LAS ORDENANZAS DE MONTES: SU PAPEL EN LA TRANSFORMACIÓN Y LA CONSERVACIÓN DEL PAISAJE FORESTAL.}

Los intereses de las comunidades rurales tienen un fuerte peso en la economía de las distintas zonas durante toda la Edad Media y la Edad Moderna, circunstancia que se refuerza con el papel de las Comunidades de Villa y Tierra y con los términos comunes entre varias localidades. Durante la Edad Media y la Edad Moderna el instrumento que reguló la gestión de los espacios forestales fue la Ordenanza de Montes, unas veces como un texto independiente y otras como un documento incluido en las Ordenanzas de la villa; normalmente tenían un fuerte carácter sancionador, prueba de que había frecuentes incumplimientos de la norma. Ahora bien, su mera existencia demuestra el interés en preservar el aprovechamiento de los espacios forestales, y han tenido un papel destacado en la permanencia de amplias extensiones de montes en toda España (GORDO ALONSO, 2007, 309-310).

Para el ámbito que nos ocupa, en 1589 Felipe II firma una Real Carta dirigida a los 26 lugares de la Merindad del Campóo de Suso (16 de patrimonio regio y otros 10 de señorío nobiliario) que afecta a los montes "de cuatro leguas de ancho y largo poco más o menos" situados en las localidades de patrimonio regio, pero en los que tenían comunidad de aprovechamientos los 26 lugares esa Merindad. Esta Real Carta se emite debido al "desorden en las cortas y talas de los dichos montes que casi están del todo destruidos y talados, lo cual conviene remediarse", pues desde hace unos diez o doce años, esto es, desde 1577-79 las justicias no habían aplicado las Ordenanzas vigentes. Sin duda alguna, el aumento de la presión fiscal y el deterioro de la situación económica general en Castilla en los últimos años del reinado de Felipe II debió estar en el trasfondo de este incumplimiento de las Ordenanzas. No obstante, la nueva Ordenanza aprobada en este momento incide en la necesidad de preservar el monte, y el 
conjunto del paisaje vegetal y las brañas o seles, por lo que se refuerzan las medidas represivas (obsérvese la precisión en la terminología, pues no pasa por alto el carácter dioico del acebo, extendiendo la protección a los individuos de ambos sexos): "que ninguno corte ningún pie de roble, ni haya, ni acebo, ni aceba, ni espina, ningún árbol en ningún sel de vacas [...] so pena de $100 \mathrm{ma}$ ravedies por cada pie [...]" (capitulo 16) (ARCHVA. PC. Pérez Alonso (F). C. 2.770-6).

Esta preocupación por el deterioro de los montes se mantuvo en la Monarquía española entre los siglos XVII y XVIII, hasta el punto de que constituye uno de los elementos más significativos del valor que los monarcas españoles conferían a la Naturaleza como soporte de la actividad económica. Así, las Ordenanzas que Felipe III firma el día uno de julio de 1611 para la villa de Montemayor de Pililla (Valladolid) y todo su distrito tienen como objetivo fundamental " [...] hacer que los términos de los montes perdidos del nuestro distrito tornen a ser montes perfectos como de antes lo eran " (ARCHVA. PC. Alonso Rodríguez (F.). C. 3.059-1). Así pues, por una parte, hay una clara conciencia de la destrucción de los montes y su transformación en tierras de cultivos, mientras que por otra existe el convencimiento de que en el pasado los montes tenían una dimensión muy superior a la del presente: ese estado es el que, idealmente, se busca recuperar.

Este espíritu es el que se puede rastrear en las Ordenanzas que desde 1518 protegen los montes de Aguilar de Campóo. Las que se firman en Madrid el 7 de abril de 1674 constituyen un buen ejemplo de estas Ordenanzas proteccionistas y ofrecen un ejemplo de aprovechamiento del monte respetuoso con su regeneración; se organizan en los siguientes puntos (ARCHVA. PC. Pérez Alonso (F.). C. 2.484-2):

- La villa pondrá guardas, a los que pagará un salario, para la vigilancia del monte; también tendrán la responsabilidad en la vigilancia del monte, de tal manera que si recibiesen dinero por permitir cortas ilegales pagarían el daño causado en el monte y además serían inhabilitados para volver a ser guardas en el futuro.

- Se establece la prohibición de cortar o traer leña o madera a la villa; la pena por incumplir esta norma será de 400 maravedíes de pena por carro de leña, 200 maravedíes por carga de leña transportada mediante animal, y 100 maravedíes por haz de leña transportada por la propia persona. En los dos primeros casos además se produce la incautación del carro y los animales utilizados. 
- Cuando se deba realizar el aprovechamiento de leña no se podrá cortar el árbol por el pie ni a media altura, solamente se autoriza el corte de ramas; así, quien cortare un árbol por el pie o le dejase sin orca ni pendón pagará 1.000 maravedíes de pena, y perderá toda la leña cortada. El monte se concibe con una perspectiva de futuro, de tal manera que la conservación del arbolado es una garantía para que en el futuro se pueda seguir realizando el aprovechamiento de leña; además, parece evidente el interés en el aprovechamiento de la madera, de mayor valor que la simple leña.

- Ningún forastero que no sea vecino en Aguilar podrá cortar leña; quien incumpla esta norma será penado con la pérdida del carro y los bueyes, y además pagará 600 maravedíes de pena en el caso de que sea localizado en el monte; si lo lleva a su casa y se le descubre en los tres meses siguientes pagará por cada carro 1.000 maravedíes; si la corta no es de leña sino de pies enteros pagará 1.000 maravedíes por cada pie, aunque si es hallado culpable en su casa la pena se reducirá 500 maravedíes.

- Se prohíbe la corta de "mimbrajos en ningún tiempo del año, so pena de 500 maravedis por cada haz".

- En caso de necesidad la villa dará leña de rama a las personas necesitadas: no sólo se refleja así la solidaridad aldeana, sino que además se evitan asaltos al monte, con el deterioro consiguiente del arbolado.

Sin duda alguna la quiebra política (y también económica) que se señalaba en los años finales del siglo XVIII y principios del XIX tiene mucho que ver con el cambio en las relaciones sociales entre las comunidades rurales y entre los vecinos. Así, los intereses particulares, que siempre han estado presentes en las relaciones económicas, cobran un nuevo sentido y pasan a ser prioritarios.

La defensa que se hace del interés particular está presente en los mismos pleitos judiciales, como es el que enfrenta en 1794 a Respenda de la Peña con Viduerna. Resulta que en 1792 los vecinos de Viduerna han realizado obras para poner en regadío y cultivar lino unas 25 has. próximas a un arroyo que procedente de la Sierra del Brezo desagua aguas abajo en el río Valdavia. El problema que se plantea es que los vecinos de Respenda dejan de disponer agua para el riego de sus cultivos como habían hecho tradicionalmente, y especialmente en verano, cuando el río baja casi seco. Así, entendemos la fuerza del alegado que realiza el defensor de los intereses de los vecinos de Respenda, Felipe Pérez; esto es, las cosas deben mantenerse como han estado hasta ahora: "Piensa con error quien crea que le es lícito hacer de sus propias cosas lo que se le antoje y no entienda que la verdadera libertad consiste en vivir con sujeción a las leyes públicas y privativas sin ofensa de tercero [...]. Los contrarios han 
pasado sin riego, conservando de secano sus tierras, y a mis parte nunca les ha faltado este beneficio, luego no hay razón con que poder autorizar la novedad que se intenta, cambiando enteramente el estado de uno y otro pueblo" (ARCHVA. PC. A. Rodríguez (Olv.). C. 1.051-3).

\section{LA ORGANIZACIÓN Y CARACTERIZACIÓN DEL PAISAJE FORESTAL EN LA EDAD MODERNA.}

Este amplio espacio serrano del Norte de Palencia, a pesar de que constituye un territorio con unas características físicas bien definidas, desde el punto de vista humano y del aprovechamiento del espacio, comparte muchos elementos con las comarcas vecinas, tanto al Norte (en Cantabria) como al Sur, en los páramos detríticos en la zona de Saldaña o en la comarca de las Loras en torno a Aguilar de Campóo. Un notable ejemplo de esta vinculación económica entre las tierras de Cantabria y la Montaña Palentina se observa en los aprovechamientos realizados en el extenso Despoblado de Pineda, que era propio de Cervera de Pisuerga y la Abadía de Lebanza, pero en el que tenían derecho de pasto con sus ganados los vecinos de 25 concejos de Palencia y otros 17 lugares de La Liébana.

Más aún, su localización en una zona montañosa orientada al Sur y relativamente alejada de las influencias marinas hace que la distribución de las especies forestales tenga un marcado carácter de escalonamiento en altitud, pero también submediterráneo, por la fuerte reducción de precipitaciones en la época estival, lo que explica la presencia ocasional de encinares (Quercus ilex sbsp. ballota) y extensos quejigares (Quercus faginea) en las zonas bajas y protegidas de la montaña y en los fondos de los valles.

Sin duda ya en los siglos XVI al XVIII la secular intervención humana ha alterado de manera muy significativa la distribución natural de la vegetación forestal, favoreciendo aquellas especies que ofrecían un mayor interés por su madera o sus frutos. No obstante, todavía es posible encontrarnos con situaciones que remiten al pasado, puesto que, por una parte no es fácil desarraigar amplias extensiones arboladas, y por otra parte el ser humano, a lo largo del tiempo lo que ha hecho ha sido construir un modelo económico en relación con el paisaje vegetal, adaptándose, en gran medida, a sus posibilidades.

De esta forma, las amplias extensiones de hayedos y robledales tienen que corresponder a una situación cercana a la natural, si bien su estructura ha sido modificada para ajustarla a un determinado aprovechamiento forestal o ganadero; por el contrario, otras especies han podido desarraigarse por intereses humanos, pero también porque al hallarse en el límite de sus posibilidades de expansión (especialmente al entrar en contacto con otras especies mejor adaptadas) tienen 
grandes dificultades de regeneración cuando los árboles son talados o sometidos a turnos de corta de pocos años. Este puede ser el caso de encinares y quejigares.

Las características físicas y climatológicas de la zona hacen que las amplias extensiones forestales que hay entre Guardo y Otero de Guardo, por ejemplo, sean comunes a localidades algo más meridionales como Mantinos o Fresno del Río. De hecho, en Mantinos se diferencian tres elementos en su paisaje vegetal: las majadas de roble (Quercus pyrenaica), el monte alto y los páramos. Las majadas suman un total de ocho (La Redondilla, Prado Laguna, Valdotillo, Bardal, Pedrosillo, Valmalo, Barcilla y San Juan de Pedrosa), que van desde 40 has. la más grande, a tan sólo dos la más pequeña, y se utilizan para el pasto y el abrigo de los ganados en invierno; el monte alto de la Flecha, también de roble, es un monte del que se obtiene madera, tanto para la construcción y reparación de las casas, como para los aperos de labranza y otros usos; y, finalmente, el tercer elemento del paisaje son unos extensos páramos, el de Intorcisa y el de San Pedro Cansoles (casi 4.000 has.) que ocupan casi el 90\% de la superficie municipal y están en su mayor parte desprovistos de vegetación arbórea, aunque sí mantienen una rica vegetación de matorrales que sirve para el pasto de los ganados, y, además, están cultivados ocasionalmente.

Es precisamente esta circunstancia la que ha provocado la desaparición de la vegetación arbórea y su sustitución por "urzales, brezales, espinales, matorrales [...]"; esta práctica del cultivo en los páramos, sin duda alguna con centeno, viene refrendada por el hecho de que algunos terrenos de páramo se califican como "eriales que no se han sembrado de mucho tiempo a esta parte por haber reconocido sus dueños ser tierra inculta". La expresión de tierra inculta remite al escaso rendimiento que se obtiene mediante su siembra, pero no implica una falta de interés agrario o ganadero. Este espacio paramero se aprovecha en relación con las necesidades de cada momento, y el hecho de que ocupe la mayor parte del término municipal justifica su cultivo, a pesar de los magros rendimientos. De forma similar en Fresno del Río la sexta parte del término municipal estaba ocupado por unos extensos páramos que ocupaban unas 1.200 has. "que no se labran por lo infructifero, presumiéndose que en lo antiguo fueron montes"; es decir, aquí existe el recuerdo de la existencia de arbolado, lo que indica una roturación no demasiado lejana en el tiempo (AGS. CME. L. 630).

En el territorio que constituye el conjunto de la montaña palentina destacan en esta época, en mayor o menor medida, tres elementos: la importancia de los pastos de alta montaña en los puertos, brañas o seles, los peñascales y los montes altos y bajos (en ocasiones transformados en majadas para el pasto del ganado). La propiedad de estos espacios eran normalmente comunal, lo que obligaba a una organización precisa de los aprovechamientos, tanto para vecinos de la 
localidad como para forasteros a los que se cobraba una renta anual por los pastos (GARCÍA FERNÁNDEZ, 1988).

Los pastos de alta montaña, con frecuencia en los puertos, permiten el pasto de extensas cabañas ganaderas, y generalmente se arriendan a ganaderos foráneos, bien de la Mesta o particulares: así, en Verdeña hasta 2.400 cabezas de ganado repartidas entre los puertos de Las Cárcavas, La Peña, Valdenievas, Las Ortigosas; en Vidrieros son 2.150 cabezas, entre los puertos de Sarnio, Cabriles, Las Lomas y Valdenievas; en Polentinos los puertos de Linares, Pendillos, Anciana y Raso permiten el pasto de 2.150 cabezas, y de forma especial en Brañosera, sus puertos permiten el mantenimiento de un total de 7.903 cabezas de ganado lanar.

Los montes constituyen el espacio más complejo, no sólo por su gran extensión, sino también por sus diversas localizaciones (en alta o media montaña) y orientaciones, así como por los diversos usos que se da a las distintas especies arbóreos. Así, pues, destacan por presentar en su composición distintas especies, con frecuencia masas mixtas, entre las que se encuentran robles albares (Quercus petraea), melojos (Quercus pyrenaica), hayas (Fagus sylvatica) y acebos (Ilex aquifolium), y, en menor medida, pero de forma muy significativa, enebros (Juniperus communis), sabinas (Juniperus thurifera), tejos (Taxus baccata) y encinas (Quercus ilex sbsp. ballota).

Los encinares son importantes desde un punto de vista fitogeográfico, y se presentan en masas monoespecíficas o mezclados con el quejigo (Quercus faginea); han llegado a nuestros días, por ejemplo en las estribaciones orientales de la Sierra del Brezo, en el Norte de Dehesa de Montejo, sobre un total de 510 has. En el siglo XVIII la presencia de encinares se confirma, en una zona muy próxima a la mencionada, a través del Catastro de Ensenada: en Castrejón de la Peña se localizan dos pequeños encinares tratados en monte bajo en el cerro de la ermita de Santa Eulalia, y otra masa de encina y roble en Cubillo de Castrejón (AGS. CME. L. 629).

También es notable la presencia del pino (Pinus sylvestris) en el municipio de Velilla de Río Carrión, bien documentado históricamente, formado por varias masas fragmentadas ascendiendo en altitud hasta los 1.700 metros (cerca de la Peña Mayor), dentro de una ladera orientada al Oeste: son un total de 275 has. En la actualidad es un pinar mezclado con roble albar y hayas, en el que están presentes serbales, mostajos, abedules, entre otras especies. En el siglo XVIII su destino se reducía a la obtención ocasional de madera para trillos, pues no se aprovechaban los pastos debido a la mala calidad del terreno (AGS. CME. L. 628). Ahora bien, su mantenimiento excepcional en este espacio está en relación con la prohibición de su corta, debido a la función protectora que cumple: 
evita las avalanchas en la ladera; de forma que si se talase este monte quedaría desprotegido todo el terreno, y la dificultad para que brotase vegetación arbórea en ese terreno haría que durante años todo el valle del Carrión estuviese expuesto a avalanchas o deslizamientos.

Ahora bien, en tanto el destino preferente de los montes es la obtención de pastos para el ganado lo habitual es que muchos hayan sido degradados y sustituidos por matorrales como argomas (Ulex europaeus), urces (Erica arborea y Erica australis), y escobas (Genista florida) que sirven de alimento al ganado en invierno. Estos matorrales pueden ser colonizados, si cesan las causan que motivaron la invasión del matorral, por especies arbóreas (Quercus pyrenaica), que representan una primera fase de regeneración: dentro de estos montes en esos casos se mantendrán distintas especies de matorral. También en Dehesa de Montejo se localiza una de las tejeras más notables de todo el Norte palentino, sobre la ladera Norte del arroyo Tosande, en una superficie de unas 122 has., en mezcla con hayas y melojos.

El interés en la preservación de la integridad de los montes, y en especial del arbolado, es tal que hay una absoluta limitación en lo que respecta a la corta de los árboles, pues en la mayor parte de los casos sólo se da un pie a cada vecino al año, y en ocasiones ni tan siquiera eso, como sucede en Lebanza: "cada vecino va al monte por lo que necesita, sin cortar ningún pie", es decir, se aprovecha la leña muerta, con lo que además se realiza un actividad de limpieza del monte muy útil para prevenir posibles incendios.

El aprovechamiento del fruto de robles y hayas, fundamentalmente, se realiza in situ por el ganado, pues como manifiestan los vecinos de Casavegas: "[...] aunque algunos años dan los árboles, el fruto de bellota y hayuco jamás se ha recogido", así como los de Redondo: "jamás se ha cogido ni aprovechado de ello (el fruto)" (AGS. CME. L. 492), o los de Velilla: "ni tampoco la hacen (la regulación) a los montes altos por razón de bellota por no producirla" (AGS. CME. L. 628); en Cervera de Pisuerga la situación es similar: "sólo en el monte Carracedo se logra tal cual año el fruto que llaman de bellota [...]" (AGS. CME. L. 491). El motivo de esta circunstancia parece que está en relación con dos hechos: en primer lugar, las primeras heladas del otoño deben perjudicar especialmente al fruto, por lo que la cosecha no será abundante; en segundo lugar, cuando madura el fruto y cae (a finales de octubre o noviembre) es el momento en que comienzan las primeras nevadas, lo que dificulta la recogida a mano, además, esto hace que se dejen los frutos en el campo para que sean utilizados como alimento por el ganado vacuno.

La ocupación del espacio por el monte en no pocos casos es total, como ocurre en Arbejal, donde entre montes, matorrales y dehesas ocupan el $100 \%$ del 
terrazgo. En cuanto al aprovechamiento del espacio están muy arraigadas las prácticas comunales, que además sirven de elemento de cohesión social. Finalmente, las posibilidades que ofrece el medio natural determinan una economía suficientemente diversificada y que, para la época, puede calificarse de próspera: no sólo se ha extendido la agricultura y la ganadería, sino que además se han empezado a construir telares en algunas localidades, mientras que en otras se fabrican cubas y carrales, para las que se utilizan tanto el roble como el avellano.

\section{La zona Noroeste en torno a Guardo.}

Una muestra del carácter central que tienen los aprovechamientos del monte en este espacio viene dado por el predominio que tiene en el terrazgo. Es un monte con una fuerte impronta humana, como se deduce del hecho de que los montes de Rabanal son descritos como "montes de leña, robles, acebo y avellanares": sin duda alguna la elevada presencia de avellanos debe relacionarse con su plantación por los vecinos (AGS. CME. L. 492). Así, en Otero de Guardo la mayor parte del terrazgo está ocupada por majadas de roble (500 has.), matorrales de urce y roble bajo ( 1.350 has.), y un monte alto de roble ( 520 has.), que en realidad está formado por tres especies destacadas: robles, acebos y hayas "que sirven de pastos para los ganados vacunos" (AGS. CME. L. 631). Los aprovechamientos del monte son los tradicionales, que, por ejemplo, en Rabanal de los Cardaños consisten el pasto del ganado, y el reparto entre los vecinos de 28 pies altos de roble y 168 carros de leña

\section{La zona central en torno a Cervera de Pisuerga y La Pernía.}

En este espacio destaca el neto protagonismo del monte con destino a la obtención de pastos para el ganado. En ocasiones la intervención humana ha modelado el paisaje forestal hasta el punto de crear dehesas, como ocurre en Casavegas y Redondo, o majadas. Además, también se han aprovechado las buenas condiciones del terreno de los valles para extender el cultivo del lino, no en vano, por ejemplo, en Celada de Roblecedo hasta 83 personas cultivan esta planta, lo que indica que todas las familias tienen algún miembro dedicado al trabajo del lino, pues en la localidad hay un total de 74 vecinos empadronados.

Es práctica común el que los pastos del monte se arrienden a foráneos, de la misma forma que aquellas localidades que poseen pastos en los puertos los arriendan a ganaderos de las llanuras del interior. El monte tiene aquí un carácter dominante en el espacio, y su impronta se refleja en los aprovechamientos, como en el caso de Verdeña, donde del monte privativo se reparten todos los años seis carros y un pie de roble; en cuanto a los carros, cuatro son de hoja para mantener los ganados en invierno, y dos de leña para quemar; además, del 
monte comuniego corresponden a cada uno de los vecinos de Verdeña y de Estalaya seis carros de leña y un pie de roble; en Celada de Roblecedo el monte se utiliza para el reparto a los vecinos de 12 carros, seis de leña y seis de hojas; mientras que en los seis puertos pastan anualmente 2.800 cabezas de ganado; este protagonismo del ganado en el territorio de la localidad ha permitido el desarrollo de una incipiente industria lanar, que se complementa con la de lienzos, pues hay un total de 15 tejedores de lienzos y lana.

Un papel destacado juega Ruesga, pues, en comunidad con Dehesa de Montejo, aprovecha el lugar de Vega de Tosande (175 has.) en el hay cuatro especies arbóreas, hayas (Fagus sylvatica), tejos (Taxus baccata), fresnos (Fraxinus excelsior), y acebos (Ilex aquifolium); los aprovechamientos van desde "poder contar a entrepierna [...] y lo que cortare sacarlo a cuestas" hasta labrarlo. Circunstancia que deja bien claro el impacto negativo en este paisaje forestal, si tenemos en cuenta que este estrecho y pedregoso vallejo llegó a ser labrado en manera periódica o permanente, aunque sólo lo fuese en el fondo del valle.

Especial significado en cuanto al carácter comunal de los aprovechamientos tiene el despoblado de Pineda, pues constituye un conjunto de "tierras de pastos y brezales bajos" que se utilizan para los pastos de verano por parte de los vecinos de 25 concejos de Palencia y otros 17 lugares de la comarca de La Liébana (Cantabria). Y es que este tipo de comunidades de pastos no sólo representan un elemento de la organización del espacio a gran escala, sino que tienen que ver con la solidaridad aldeana, y se remontan a la época medieval, cuando los aprovechamientos comunes entre aldeas estaban mucho más generalizados, porque implicaban un tipo de relaciones social muy estrecha. Este despoblado, así pues, corresponde a un espacio de alta montaña localizado en la actual Reserva Nacional de Fuentes Carrionas hasta el límite con la Comunidad de Cantabria.

La presencia de los pastos tiene que ver tanto con la deforestación realizada por el ser humano a lo largo de los siglos, como con la dificultad para que la vegetación arbórea pueda crecer, una vez roturado el monte, en este terreno de alta montaña. El desarrollo del brezo se justifica porque es uno de los matorrales propios de la etapa de sustitución de robledales, y por el hecho de este arbusto lo come el ganado en la época del verano, mientras que en invierno no se realiza ningún aprovechamiento "porque se cubre de nieve".

También la localidad de Matabuena es un buen ejemplo del recurso a la comunidad de bienes, pues tiene seis términos comuneros, sobre una superficie de 1.000 has., con otras tantas localidades situadas en las cercanías: Cillamayor, Bustillo de Santullán, Nava de Santullán, Santa $\mathrm{M}^{\mathrm{a}}$ de Nava, y Revilla de Santullán. 


\section{La zona oriental entre Barruelo de Santullán y la Braña.}

De nuevo el monte actúa como un referente en el espacio y en relación con los aprovechamientos que de él se derivan. Una de las poblaciones que tiene una mayor superficie forestal es Mudá que cuenta con dos grandes montes, uno privativo y otro comunero. El privativo tiene 4.200 fanegas (2.100 has.) con "robles, carrascales y espinos", si bien algo más del 15\% está cultivado: esta roturación del monte es reciente puesto que en 1752 cuando se hizo la primera averiguación del Catastro los vecinos trataron de ocultar estas 680 fanegas cultivadas, y sólo en una nueva averiguación salió a la luz el terrazgo cultivado, incluyéndose como rectificación en el Catastro. El monte comunero alcanza las 8.000 fanegas de superficie (algo más de 4.000 has.), y aquí la ocultación fue muy pequeña, de apenas el $4 \%$, una parte de la cual pertenecía a tierras cultivadas.

Los aprovechamientos del monte corresponden al pasto del ganado y a la obtención de leña para quemar, de forma muy similar a como ocurría en el área de Cervera y Guardo. Así, en San Cebrián de Mudá, por una parte en los montes pastan anualmente un total de 2.000 cabezas de ganado, y por otra se hacen aprovechamientos de leña y hojas, que consisten en dos suertes en el monte privativo, una de hoja y otra de leña, de las que se reparten un carro a cada vecino; mientras que en el monte comunero se hacen todos los años tres suertes, dos de leña y una de hoja, lo que permite repartir a cada vecino cuatro carros de leña y dos de hoja. En Valle de Espinosillo las suertes permiten que cada vecino reciba cuatro carros, dos de hojas y dos de leña.

\section{LA ÚLTIMA TRANSFORMACIÓN DEL MONTE EN EL SIGLO XX.}

La diversidad de aprovechamientos en el medio vegetal sostenida en largos períodos de tiempo, determina dinámicas vegetales diferenciadas que dan lugar a formaciones vegetales distintas, incluso en zonas cercanas en el espacio; así mismo, la mayor o menor intensidad de estos aprovechamientos (o la mayor presión sobre una especie que sobre otra), hace que una masa forestal evolucione en un sentido o en otro. El cambio de relación campesino con el monte que se produce desde mediados del siglo XIX (época de las desamortizaciones), y, especialmente, la radical transformación del medio rural y sus dedicaciones desde mediados del siglo XX, hacen que el monte experimente una dinámica diferente a la que había mantenido durante los siglos anteriores: se introducen nuevas especies o se favorecen unas especies forestales a costa de otras, reduciéndose la superficie de pastos; aumenta la complejidad de los montes y su estructura al reducirse las cortas de leña o ampliarse los turnos de corta. 
Así, la dinámica del Monte Aguilar en Aguilar de Campòo (932 has. de superficie forestal) ejemplifica en la actualidad la distribución de especies arbóreas a través de una presión antrópica diferenciada sobre éstas: mientras el hayedo asociado con el roble albar (77 has.) y el roble albar (161 has.) son marginales y se refugian en la parte superior de la ladera por encina de los 1.200 metros, el melojo ocupa la mayor superficie (605 has.) del terreno a cotas bajas y medias (BDN, 2003).

Ahora bien, el medio físico nunca pierde su protagonismo en esta dinámica (reforzándose este protagonismo cuando disminuye la presión humana), de tal manera que, por ejemplo, mientras la vertiente Norte (más fría y húmeda) de la Peña Redonda está cubierta por un hayedo (418 has.), toda la vertiente Sur (municipio de Castrejón de la Peña) corresponde a un extenso matorral (1.386 has.). De la misma manera, en la ladera Sur del Pico Robladillo (Dehesa de Montejo) hacia el arroyo Tosande domina un pequeño encinar (112 has.), mientras que la orilla Norte de este mismo arroyo ya está ocupada de nuevo por las hayas (122 has.).

A lo largo del siglo XX, especialmente desde la segunda mitad, la intervención en el monte no sólo cambia de signo, por el menor interés de los aprovechamientos ganaderos, sino que también se reduce, pues el monte adquiere un carácter cada vez más marginal en relación a otras dedicaciones económicas de la población. De esta forma, en el paisaje vegetal de la Montaña Palentina se señalan varias dinámicas diferenciadas: unas de estabilización y otras de progresión de la vegetación. Junto a esta circunstancia veremos cómo hay modificaciones entre las especies que pueblan el conjunto de la Montaña Palentina, pues frente a las tradicionales cobran auge el pino (Pinus sylvestris), y sabinas (Juniperus thurifera) y enebros (Juniperus communis), en su mayor parte fruto de repoblaciones en zonas de robledales (si bien también se señalan masas naturales, como el pinar de Velilla de Río Carrión, en una ladera, entre los 1.200 y los 1.500 metros de altitud). Así, por ejemplo, en Triollo los pinares de Pinus sylvestris alcanzan ya unas 600 has.; al mismo tiempo que el haya incrementa su zona como resultado de una expansión natural sobre terrenos de roble.

Así pues, el paisaje forestal tiene, por una parte, unos elementos muy similares a los que ya eran característicos de este espacio entre los siglos XVII y XVIII, pero, por otra parte, hay cambios importantes en las formaciones vegetales y en su composición, que se explican por una dinámica natural de largo tiempo y de tipo antrópico: la diferente utilidad que ha tenido el monte en los últimos 50 años ha hecho que reciba un tratamiento bien distinto al que recibía en la época moderna. Más aún, la intervención humana se ha acrecentado a partir de la entrada en acción de los organismos oficiales (PFE, ICONA) ampliando la superficie forestal de ciertas especies. 


\section{CONCLUSIONES.}

En la montaña del Norte de Palencia durante siglos estuvieron muy arraigadas las prácticas comunales. Un medio natural en el que el monte era predominante determinó una organización del territorio que debía preservar el monte poblado con árboles de buena talla, porque constituía una garantía de futuro para la comunidad, pero además era preciso conciliar los deseos de la comunidad con los intereses de los ganaderos, tanto locales como foráneos. De esta manera, en general los espacios situados a mayores altitudes, donde la vegetación arbórea era más escasa y resultaba más difícil el acceso para el aprovechamiento de la madera, fueron reservados a pastizales.

La preservación del bosque no sólo favorecía una actividad económica consistente en el aprovechamiento de leña y hojas por los vecinos, sino que además permitía unos saneados ingresos a las Haciendas locales a partir de la venta de madera; de esta manera era necesario limitar las cortas en el monte para permitir el crecimiento de los árboles; y, finalmente, en las zonas de fuertes pendientes el mantenimiento de la vegetación arbórea sujetaba el suelo, retenía las aguas y evitaba desprendimientos del terreno. Ahora bien, estas prácticas conservacionistas también estuvieron en las base de los conflictos con los propietarios de ganado ovino y con los agricultores; los primeros, interesados en los pastos que podían obtenerse sobre terrenos forestales, y los segundos deseosos de ampliar el terrazgo cultivado, única solución para mantener la población.

De esta manera parece que el péndulo se inclinará de un lado u otro dependiendo, primero, de las circunstancias económicas (años de malas cosechas en las llanuras de Castilla estimularán la roturación en la montaña para obtener algunas magras cosechas de cereales panificables y para ampliar las zonas de pastos), $y$, en segundo lugar, de las condiciones naturales, pues una vez cultivado durante varios años un terrazgo de mala calidad era frecuente que se abandonase, con lo que era invadido por un matorral de escaso interés para el ganadero, pero que al ocupar grandes áreas tenía un indudable interés. El uso tradicional del fuego para eliminar el arbolado debe estar en el origen del mantenimiento de estas extensas áreas de matorral. Esto reducía las posibilidades de recuperación del monte, que tendía a fragmentarse en función del medio físico y los intereses de las diferentes comunidades rurales: la ampliación de las posibilidades económicas en una localidad (agricultura, ganadería, artesanía) aseguraba una pervivencia de un medio forestal menos intervenido, al menos durante algún tiempo, y generalmente más extenso. Así, las zonas menos montuosas, formadas por extensas parameras, serán las primeras que reduzcan sus montes para destinarlos al cultivo; mientras que los espacios más abruptos y cercanos a los pueblos conservarán montes extensos, pero fragmentados por campos cultiva- 
dos o majadas, y aquellos otros montes alejados de las poblaciones pervivirán con éxito hasta épocas recientes.

\section{FUENTES Y BIBLIOGRAFÍA}

\section{Fuentes}

ARCHIVO GENERAL DE SIMANCAS (AGS). DiRECCIÓN GENERAL DE RENTAS. $1^{a}$ remesa (Catastro del MARQUÉS DE LA ENSENADA). (CME). Libros nº 357, 487, 493, 491, 492, 494, 628, 629, 630, 631.

ARCHIVO DE LA REAL CHANCILleRÍA DE VAlladolid(ARCHVA). Pleitos Civiles. Alonso Rodríguez (Olv.). Caja 764-5.

ArchVA. Planos y Dibujos. Óleos, 1.

ArChVA. Pleitos Civiles. Alonso Rodríguez (D.). Caja 356-1.

Archva Pleitos Civiles. Alonso Rodríguez (Olv.). C. 1.051-3.

ArCHVA. Pleitos Civiles. Alonso Rodríguez (F.). C. 1.250-6

ArchVA. Pleitos Civiles. Alonso Rodríguez (F.). C. 3.059-1.

ArchVA. Pleitos Civiles. Fernando Alonso (F.). C. 2.224-1.

ArchVA. Pleitos Civiles. Pérez Alonso (F.). C. 1.021-1.

ArchVA. Pleitos Civiles. Pérez Alonso (F.) C. 2.484-2.

ArChVA. Pleitos Civiles. Pérez Alonso (F). C. 2.770-6

ArchVA. Pleitos Civiles. Pérez Alonso (F.) C. 3.304-4

Banco de DAtos De la NATURALEZA: Mapa Forestal de España. Escala 1:50.000. Provincia Palencia, Madrid, 2003.

\section{Bibliografía}

CABERo DiÉGUEZ, V. (1990): «Las montañas septentrionales», en Geografía de Castilla y León. Volumen 8. Las comarcas tradicionales, Valladolid, Editorial Ámbito, pp. 16-75.

EZQUERRA BOTICARIO, FCO. Y GIL SÁNCHEZ, L. (2004): «La transformación histórica del paisaje forestal en la Comunidad de Cantabria», en Tercer Inventario Forestal Nacional. 1997-2006, Madrid, Organismo Autónomo Parques Nacionales, 161 pp.

Florido TrujILlo, G. (2004): «Uso social y evolución del bosque atlántico. Pasado y presente en el ámbito del Bajo Deba guipuzcoano», Papeles de Geografía, 39, pp. 59-80.

GARCÍA FERNÁNDEZ, J. (1998): Sociedad y organización tradicional del espacio en Asturias, Gijón, Editorial Silverio Cañada.

GARCÍA FERNÁNDEZ, J. (2002): «La explotación de los montes y la humanización del paisaje vegetal (cuestiones de método previas)», Investigaciones Geográficas, 29, pp. 5-21.

Gordo Alonso, F. J. (2007): «De las ordenanzas al Catálogo de los Montes de Utilidad Pública», en Gil SÁnchez, L. y Torre Antón, M., Atlas Forestal de Castilla y León, León, Edita Junta de Castilla y León, pp. 309-332.

MANUEL VALDÉS, C. Y GIL SÁNCHEZ, L. (1988): «La transformación histórica del paisaje en España», en Segundo Inventario Forestal Nacional. 1986-1996. España, Madrid, Organismo Autónomo Parques Nacionales, pp. 15-104. 
MANUEL VALDÉS, C. (1999): «Características y transformaciones de la gestión forestal en España (siglo XVI-XIX)» en MARÍN PAGEO, F. et al., Los montes y su historia. Una perspectiva política, económica y social. $I^{\text {as }}$ Jornadas forestales, Huelva, Edita Universidad de Huelva, pp. 33-49. 